\title{
ESTUDO ANATOMICO DO XILEMA SECUNDARIO E DA CASCA DE Acacia recurva BENTH. (LEGUMINOSAE MIMOSOIDEAE)
}

Josē Newton Cardoso Marchiori

Departamento de Ciências Florestais. Centro de Ciências Rurais. UFSM. Santa Maria, RS.

RESUMO

0 trabalho descreve a estrutura anatômica da madeira e da casca de Acacia recurva Benth.

A microestrutura da madeira e casca desta planta ē compa rada com a de outras espēcies sul-americanas do mesmo gēnero.

SUMMARY

MARCHIORI, J.N.C., 1982. Anatomical study of secondary xylem and bark of Acacia recurva Benth. (Leguminosae Mimosoideae). Ciência e Natura (4):95-105.

This study describes the wood and bark of Acacia recurva Benth. The anatomical structure of this liana is compared with some other South-American species of the same genus.

INTRODUÇAO

A gênero Acacia (Tournef.) Miller tem ampla distribuição geogräfica e compõe-se de centenas de espécies, muitas das quais de expressivo valor na produção de madeira e tanino.

A acācia-negra (Acacia mearnsii De Wild), Acacia meZanoxy Ion R.Br., Acacia dealbata Link. e outras espēcies australianas por exemplo, são cultivadas em muitos países. A anatomia do xilema e da casca, e as propriedades tecnológicas destas madeiras são bem conhe cidas. As espécies sul-americanas deste gênero, entretanto, não apre sentam a mesma importância econômica e foram pouco estudadas sob es ses aspectos.

0 presente trabalho trata da descrição anatômica da madei ra e da casca de Acacia recurva Benth., espēcie nativa no sul do Bra sil.

\section{REVISÃO DA LITERATURA}

0 gēnero Acacia compõe-se de aproximadamente 750 espécies, dispersas amplamente em regiões tropicais e subtropicais da América, Africa, Asia e Austrālia. Numerosas espēcies deste gēnero são culti vadas em todo o mundo para fins ornamentais, fixação de dunas, ou pa ra a produção de madeira, lenha, goma', tanino, essências para perfu maria e material forrageiro (BURKART, 3, 4). 
A morfologia floral e dos órgãos vegetativos difere marca damente entre as espécies de Acacia. Com base em critérios taxonômi cos clāssicos, BENTHAM (1) agrupou as espécies deste gênero em cin co sēries: Vulgares, Grummiferae, Botryocephalae, Pulchellae e Phyllo dineae. Mais recentemente, VASSAL (15), fundamentado em caracteres filéticos da morfologia da semente e plāntulas, prōpos uma nova clas sificação natural da tribo Acacieae, restaurando o gênero monotípi co Faidherbia e dividindo o gēnero Acacia nos subgēneros Aculeife rum, Acacia e Heterophyllum.

Segundo VASSAL (15), Aculeiferum corresponde à sērie VuI gares Benth., o subgênero Acacia compreende as espécies da sērie Gummiferae Benth. com excessão de $A$. albida e Heterophyllum reune as espécies das séries Puzchezrae, Botryocephazae e Phyzlodineae de Bentham.

o subgênero HeterophylZum Vassal é endêmico da Austrālia e forma um grupo natural dentro do gênero, distinguindo-se claramen te das espécies africanas e americanas (PETTIGREW \& WATSON, 13). As espécies deste subgênero, em virtude de sua maior importāncia eco nômica, são melhor conhecidas anatomicamente.

$\mathrm{Na}$ América e Africa, apenas os subgêneros Acacia e Aculeife rum apresentam espécies nativas. Para estas espécies são escassas as informações anatômicas.

Cozzo (6) estudou a estrutura do xilema de 11 espécies de Acacia nativas da Argentina, pertencentes aos dois subgêneros acima mencionados. Este autor não encontrou diferenças significantes entre as espécies estudadas, concluindo que Acacia é um gênero homogêneo sob o ponto de vista da Anatomia da Madeira.

MARCHIORI (11), pesquisando a anatomia da madeira e casca de 3 espécies nativas no Estado do Rio Grande do Sul, encontrou se melhança estrutural entre as duas espécies pertencentes ao subgēne ro Aculeiferum, e diferenças marcantes entre estas e Acacia caven (Mol.) Mol., do subgênero Acacia. 0 mesmo autor sugere que as dife renças anatômicas observadas podem ser consideradas como caracteres filêticos vālidos para a taxonomia da madeira no gênero Acacia, mas ressalta que é necessário uma pesquisa mais ampla, com um maior nū mero de espécies dos dois subgêneros.

Acacia recurva Benth. pertence à subgênero Aculeiferum. Trata-se de uma liana lenhosa e armada, nativa no planalto meridio nal do sul do Brasil. E espécie heliófila e seletiva higrófila, mui to abundante e frequente em associações secundārias como capoeiras, capoeirões, orlas de matas e de rios, submatas semidevastadas de pi nhais, clareiras de matas e beira de estradas. Na mata primäria sua ocorrência é mais rara (KLEIN, 10). 
MATERIAL E METODOS

Foram estudadas amostras de madeira e de casca de 4 indi vĩduos. Estas amostras, bem como as respectivas exsicatas de mate rial botânico, encontram-se guardadas no Herbārio do Departamento de Ciências Florestais da UFSM segundo os seguintes registros:

- HDCF 96 (28.02.79), Passo Fundo, Floresta Nacional. Pinhal.

- HDCF 201 (10.01.81), Passo Fundo, Floresta Nacional. Capoeira.

- HDCF 288 (11.03.81), Agudo, Nova Bohêmia. Mata ciliar do Jacuí.

- HDCF (15.07.81), Passo Fundo, Floresta Nacional. Mata nativa.

De cada amostra de madeira foram preparados três bloqui nhos para a obtenção de cortes anatômicos nos planos transversal, longitudinal tangencial e longitudinal radial. Os bloquinhos foram retirados na periferia do alburno e amolecidos por fervura em água. os cortes anatômicos foram realizados em micrótomo de deslizamento, com espessura nominal de $20 \mu \mathrm{m}$.

Os bloquinhos para a obtenção de lâminas da casca foram inicialmente incluídos em celoidina. Foram obtidos cortes anatômicos em plano transversal, radial, e em diferentes profundidades do pla no tangencial da casca.

os cortes anatômicos de madeira e casca foram coloridos com vermelho-acridina, crisoidina e azul-de-astra, e montados em 1ạa minas permanentes com "Entellan".

A dissociação de fragmentos de madeira e de casca foi rea lizada pelo método de Jeffrey. O material macerado foi colorido com safranina.

A determinação dos dados quantitativos da estrutura anatô mica da madeira foi realizada segundo as recomendações da COPANT(5), com as alterações propostas por BURGER (2). As determinações his to métricas do xilema seguiram a metodologia utilizada por TEIXEIRA(16) e MARCHIORI (11).

Para a casca foram determinados apenas o comprimento e 0 diâmetro médio de elementos crivados e de fibras floemáticas, com base em 20 medições em cada amostra, no total de 80 medições de ca da carāter anatômico.

DESCRIÇAO DA MADEIRA

Caracteres gerais e organolépticos

Madeira de cor amarelada com alburno e cerne indistintos, macia ao corte, pouco brilhante, sem odor e gosto característicos, de fácil trabalhidade, de grã direita, veteado pouco atraente, e de textura fina.

Caracteres macroscópicos

Poros:Em distribuição semi-difusa, muito numerosos, de muito peque 
nos a muito grandes, solitários e em mūltiplos radiais de poucos po ros, frequentemente com conteúdos. Poros de lenho inicial visíveis a olho nu; poros de lenho tardio apenas perceptíveis sob lente. Li nhas vasculares retilíneas, ocasionalmente obstruídas por conteúdos.

Parênquima axial: Escasso, visível a olho nu apenas no lenho tardio; dos tipos paratraqueal vasicēntrico, aliforme, às vezes confluente.

Parênquima radiaz: Em secção transversal os raios são quase invisí veis a olho nu, finos, pouco freqdentes. Em plano tangencial são in visíveis a olho nu, visíveis sem dificuldades sob lente, baixos, não estratificados. Espelhado pouco contrastado.

Anéis de crescimento: Distintos, individualizados pela porosidade se mi-difusa e pela cor mais clara do lenho inicial.

outros caracteres: Canais secretores axiais, horizontais, e líber incluso, ausentes. Máculas medulares não foram observadas.

\section{CARACTERES MICROSCOPICOS}

Vasos: Porosidade semi-difusa (Figura 1 a). Poros de muito poucos a numerosissimos ( $2-12-78$ poros $/ \mathrm{mm}$ ), de extremamente pequenos a grandes ( 8 - $91-295 \mu \mathrm{m}$ de diāmetro tangencial), de paredes espes sas $(3-4,7-10 \mu \mathrm{m})$; solitārios, em mūltiplos radiais e em múltị plos racemiformes. A grande amplitude dos valores acima mencionados deve-se à variação no diāmetro de poros em um mesmo anel de cresci mento, e à formação de mūitiplos racemiformes com numerosos poros de diâmetro extremamente pequeno. Os poros solitārios tem secção cir cular ou oval, apresentando neste caso, o eixo maior na direção ra dial ou tangencial. Os agrupamentos radiais e racemiformes de poros compõem-se geralmente de um ou mais poros de maior diâmetro, de sec ção oval, e de vārios poros menores, de secção poligonal.

Elementos vasculares de muito curtos a curtos (133 - 295 $430 \mathrm{~mm}$ ), de paredes desprovidas de espessamentos espiralados e ou tros ornamentos especiais. Apēndices geralmente presentes em uma das extremidades ou em ambas. Os apêndices são curtos $\left(\begin{array}{lllll}10 & -48 & 145 & 4 m\end{array}\right)$. Placa de perfuração do tipo simples, em posição transversal ou bas tante inclinada, em àngulos de até $20^{\circ}$ em relação ao eixo do vaso. Vasos desprovidos de tilos, mas comumente com gomo-resina na região do cerne.

Pontuado intervascular alterno. Pontuações intervasculares geralmente de forma poligonal devido ao seu grande número, de peque nas a médias $(5-7,4-10 \mu \mathrm{m})$. Abertura extrena estreita, em forma de fenda, horizontal, inclusa, ornamentada. Abertura interna de for ma lenticular, inclusa ou freqdentemente curto-coalescente atē 4 pon tuações, horizontal ou levemente obliqua. 
Pontuados rádio-vascular e parênquimo-vascular igualmente alternos. Pontuações rádio-vasculares de forma oval, pequenas ( 4 $5,23-7 \mu \mathrm{m})$, com abertura em forma de fenda oval horizontal. Pon tuações parênquimo-vasculares, de forma oval ou frequentemente es tendidas horizontalmente; de pequenas a médias $(5-6,6-11 \mu \mathrm{m})$, com abertura semelhante à das pontuações intervasculares.

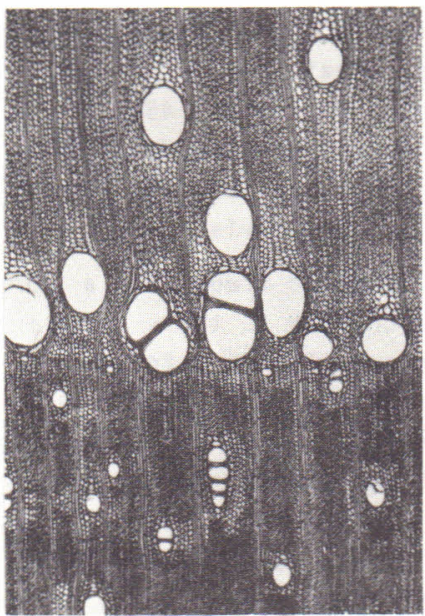

a

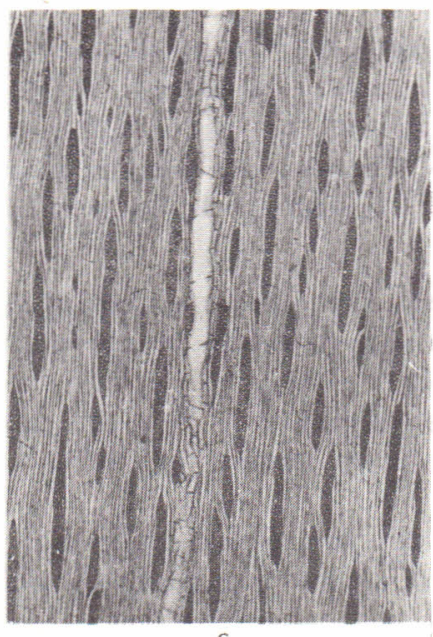

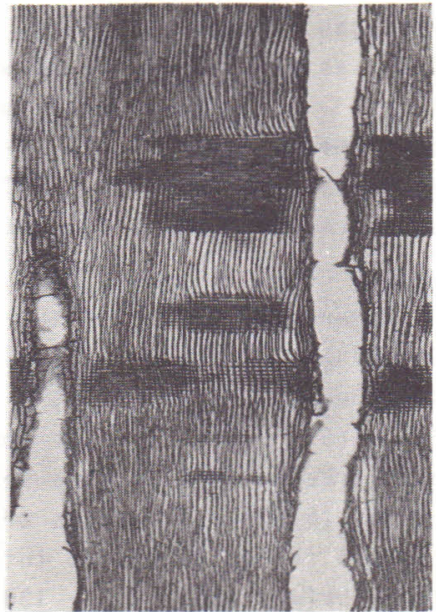

b

Figura 1. Fotografias da madeira de Acacia recurva Benth. a, secção transversa 1(32X). b, secção longitudinal ra dial $(32 x)$. c, secçãolon gitudinal tangencial(32x).

Parênquima axiaz: Pouco abundante $(12,6 \%$ do volume), tipicamente pa ratraqueal, principalmente vasicêntrico, mas taniẻm dos tipos escas so, aliforme e, ocasionalmente, confluente. Ocorre prênquima apotra 
queal marginal no início do anel de crescimento, juntamente com fi bras de paredes finas.

A identificação de cēlulas parenquimáticas e, por conse guinte, a caracterização dos tipos de parênquima, nem sempre é pos sível de ser realizada em secção transversal devido à ocorrência de fibras de paredes finas concentradas principalmente na periferia do parênquima paratraqueal, do qual muito se assemelha. Para a inter pretação da distribuição do parênquima axial e para fins de histome tria, as secções longitudinais são indispensāveis.

Células de parēnquima fusiforme de $83-269-458 \mu \mathrm{m}$ de comprimento, por $10-17,5-30 \mu \mathrm{m}$ de diâmetro. Células de parênqui ma seriado de 20 - $119-250 \mu \mathrm{m}$ de comprimento, por 8 - 16 - $28 \mu \mathrm{m}$ de diàmetro, em 2 até 5 células parenquimáticas por série.

Raios: Todos do tipo normal, homogêneos; de pouco frequentes a mui to numerosos $(3-5,7-10 \mathrm{raios} / \mathrm{mm})$, desprovidos de tipos especiais de cēlulas. Raios uni-seriados muito escassos $(1,35 \%$ do total), ex tremamente baixos $(10-64-263 \mu \mathrm{m})$, de extremamente finos a muito finos (5 - 9,5 - $23 \mu \mathrm{m}$, e com 1-5 - 14 cēlulas. Raios multi-seriados mais freqdentemente tetra-seriados $(48,6 \%$ dos raios), poucos bi-se riados $(5,8 \%)$ e numerosos tri-seriados e com mais de 4 células de largura (cerca de $22 \%$ do total para cada tipo); de extremamente bai xos a baixos $(53-350-1385 \mu \mathrm{m})$, de extremamente finos a finos (8 - 31 - $50 \mu \mathrm{m}$ de diâmetro), e com 5 - 31 - 118 células de altura.

Fibras: Tecido fibroso procminente ( $66,5 \%$ do volume). Fibras libri formes septadas, frequentemente gelatinosas, de extremamente curtas a muito curtas $(280$ - $709-1320 \mu \mathrm{m})$, de estreitas a médias (8 - 16$33 \mu \mathrm{m})$, de paredes muito delgadas a delgadas $(1,25-2,8-6,25 \mu \mathrm{m})$. As fibras apresentam diminutas pontuações simples, que são mais abun dantes em faces radiais da parede celular. A madeira não apresenta qualquer tipo de estratificação.

Outros caracteres: Canais secretores, tubos laticíferos e taninífe ros, e líber incluso, não foram observados. Máculas medulares ocasionais. Não ocorre qualquer tipo de estratificação.

Cristais de oxalato de cālcio em câmaras, de 16 a 24 por série, concentrados no término do anel de crescimento, sem formar, contudo, um envoltōrio completo.

Anéis de crescimento bem definidos pela porosidade em anel semi-circular e pela formação de séries de cristais em câmaras no final do lenho tardio.

DESCRIÇAOO DA CASCA

Casca interna

Casca interna de espessura bastante variāvel, comumente 
entre 150 e $400 \mu \mathrm{m}$. Líber duro presente, com abundância e dispos $\underline{i}$ ção bastante variāveis nos espécimes estudados, representado por pe quenos grupos de fibras floemáticas ou curtas faixas tangenciais de 2 a 4 cēlulas de espessura. 0 alinhamento tangencial destas faixas é fracamente definido (Figura 2 a).

Fibras floemáticas gelatinosas, não septadas, de 1190 1364 - $1490 \mu \mathrm{m}$ de comprimento por 7,5 - 11,1 - $15 \mu \mathrm{m}$ de diâmetro.

Elementos crivados de 223 - 327 - $400 \mu \mathrm{m}$ de comprimento,e 20 - 27,8 - $35 \mu \mathrm{m}$ de diâmetro tangencial; isolados ou em grupos tan genciais de numerosos tubos crivados em meio ao parēnquima axial. Placas inclinadas a quase verticais; compostas por 15 a 25 áreas cri vadas em arranjo reticulado, raramente escalariforme. Poros pequenos, bem visíveis ao microscópio, numerosos por área crivada (Figura 2c).

Parênquima axial abundante. Células acompanhantes despro vidas de inclusões inorgânicas.

Raios homogêneos, semelhantes aos do xilema (Figura 2 d), separados em secção transversal por 3 a 12 células axiais. Células de parênquima radial desprovidas de inclusões inorgânicas.

Casca mediana

Proeminente, de 900 a $2000 \mu \mathrm{m}$ de espessura. 0 colapso de tubos crivados ocorre ao mesmo tempo em que se formam novas células parenquimáticas e se diferenciam as células oleîferas. Estas são mais longas que as demais células de parênquima axial; em secção transversal formam pequenos grupos de células nitidamente maiores no centro de certas regiões de líber tenro (Figura 2 b).

Na casca mediana os raios tem curso irregular. Inicialmen te as células de parênquima radial alargam-se em direção tangencia?; próximo à região de esclerificação verifica-se, em muitos raios, uma intensa divisão celular segundo planos anticlinais, de modo a ser produzido o crescimento dos raios em comprimento e diâmetro, e a se paração dos feixes de fibras.

As células de parênquima radial dividem-se anticlinalmen te, à semelhança dos raios. Em posição mais externa, grande parte das células parenquimáticas tornam-se cristalíferas, produzindo um monocristal romboédrico de oxalato de cálcio.

ocorre, por fim, a esclerificação das células de parênqui ma e a formação de um cilindro esclerenquimático que ocupa cerca da metade da espessura da casca mediana. Esta região confere proteção mecânica aos tecidos internos e compõe-se de macroesclereidas e cế lulas pētreas frequentemente cristalifferas, feixes floemáticos e sê ries de parênquima cristalífero adjacente pouco esclerosado, e cu nhas bastante irregulares de cēlulas não esclerosadas que podem, oca sionalmente, atravessar o cilindro esclerenquimātico. 


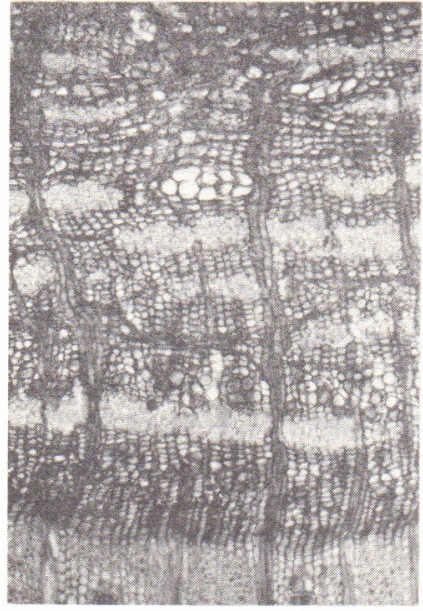

a

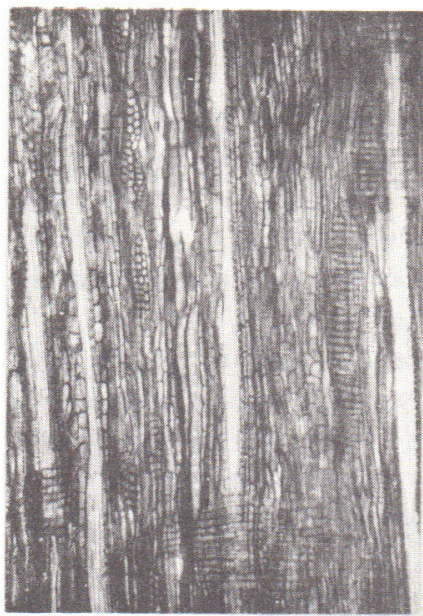

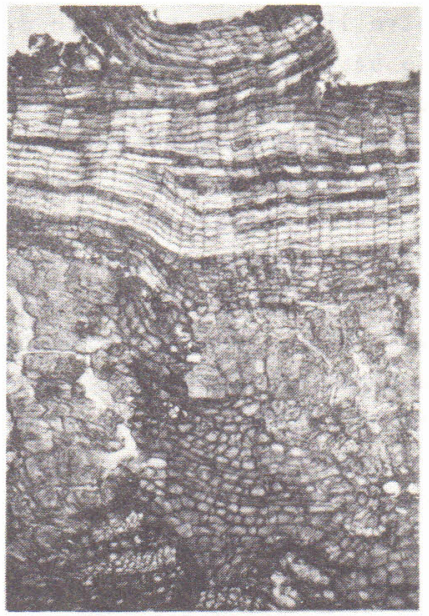

b

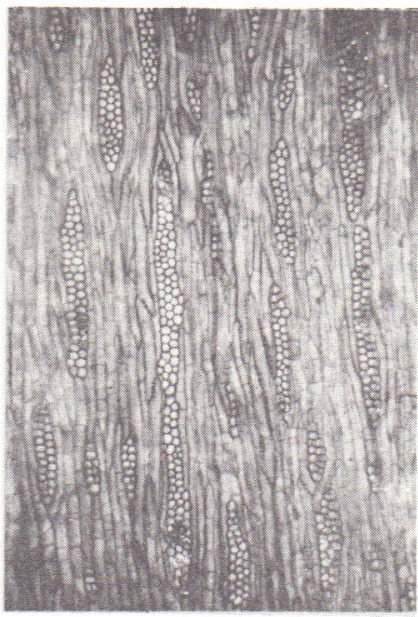

d

Figura 2. Fotografias da casca de Acacia recurva Benth. a, Secção transversal da casca interna $(85 X)$. b, Secção transversal das cascas mediana e externa ( $85 X)$. c, Secção longitudi nal radial da casca interna $(85 \mathrm{X})$. d, Secção longirudinal tangencial da casca interna $(85 X)$.

Em espécimes jovens de casca observam-se externamente a esta região, ithas de fibras corticais, e resquícios de parênquima cortical com cēlulas cristalifferas abundantes. 
A casca mediana termina em estreito feloderma.

Casca externa

Estreita nos espécimes estudados, com cerca de 300 a 500 $\mu \mathrm{m}$ de espessura.

Células de suber com faces tangenciais de parede ligeira mente mais espessas do que as radiais. Células felóides frequentes, isoladas ou em curtas linhas tangenciais.

\section{ANALLISE DA ESTRUTURA ANATÖMICA DA MADEIRA}

A estrutura anatōmica da madeira de Acacia recurva Benth. concorda com as características gerais citadas por METCALFE \& CHALK (12) para as Mimosāceas.

A madeira estudada mostra grande semelhança estrutural com as espēcies do subgēnero Aculeiferum descritas por MARCHIORI (11). Segundo este autor, a presença de fibras libriformes septadas, parên quima axial pouco abundante, presença de fibras vivas de paredes finas na periferia do parênquima paratraqueal, e raios predominantemente uni e bi-seriados, são características comuns para as espēcies do subgênero Acuzeiferum. Comenta ainda que para o subgênero Acacia é característico a presença de parénquima axial abundante do tipo pa ratraqueal em faixas, fibras não septadas de paredes espessas e raios multi-seriados largos.

Em Acacia recurva são encontradas fibras desde cerca de $300 \mu \mathrm{m}$, correspondendo aproximadamente à altura das sēries de parên quima axial e cēlulas fusiformes de parênquima, até fibras tîpicas, com mais de $1 \mathrm{~mm}$ de comprimento. As fibras menores localizam-se na periferia do parênquima paratraqueal, de cujas cêlulas distinguem-se apenas em seç̧ōes longitudinais pela presença de septos. Estas fi bras curtas frequentemente armazenam grãos de amido.

A ocorrência destas fibras curtas e de lumem largo, asso ciadas ao parênquima paratraqueal foi observada inicialmente por JANSSONIUS (9), que as considerou como carāter diferencial vālido entre madeiras de Mimosoideae e Caesalpinioideae.

FAHN \& LESHEM (7) observaram que fibras vivas armazenado ras de substâncias de reserva ocorrem principalmente em arbustos e subarbustos, podendo ser um carāter adaptativo da vegetação lenhosa de habitats desfavorāveis. HARRAR (8), por outro lado, constatou que a presença de grãos de amido em fibras estā correlacionada com parên quima axial extremamente escasso ou ausente. 0 hábito vegetativo e a estrutura anatōmica de Acacia recurva correspondem às observações destes autores.

ANALISE DA ESTRUTURA ANATŌMICA DA CASCA

A casca de Acacia recurva Benth. apresenta as seguintes ca 
racterísticas principais:

- Liber duro presente na casca interna sob a forma de fi bras floemáticas típicas, e nunca como cēlulas pétreas.

- Fibras agrupadas em feixes isolados que tendem ao alinha mento tangencial.

- Concentração de monocristais romboēdricos de oxalato de cālcio em câmaras cristalīferas em torno dos feixes de fibras floemáticas.

- Ausência de canais secretores.

- Elementos crivados dotados de placas compostas, com äreas crivadas em arranjo escalariforme ou reticulado.

- Raios sempre homogêneos, multi-seriados em sua maioria, e desprovidos de canais.

- Crescimento de dilatação moderado, verificando-se a for mação e concentração de cēlulas pétreas e macroesclerō citos na região mais externa da casca mediana.

Estas características anatômicas são também citadas por ROTH (14) como gerais para as Mimosáceas. Apesar da semelhança ge ral na estrutura anatômica da casca nesta família botânica, ocorrem caracteres diferenciais suficientes para a identificação de espécies (MARCHIORI, 11 ).

Para o gênero Acacia, MARCHIORI (11) reconheceu diferen ças de valor taxonômico para os subgêneros Aculeiferum e Acacia. Se gundo o mesmo autor, as espēcies do primeiro destes subgēneros cá racterizam-se pela presença de fibras libriformes septadas, líber du ro em feixes isolados que tendem ao alinhamento tangencial, e pela ausência de monocristais prismáticos de oxalato de cálcio em célu las de parênquima radial. Para o subgênero Acacia, Marchiori cita a presença de lỉber duro em faixas tangenciais regulares interrompidas apenas por raios floemáticos, presença de cristais em raios e fibras floemāticas não septadas.

A casca de Acacia recurva assemelha-se estruturalmente à das espécies descritas por MARCHIORI (11), pertencentes ao subgêne ro Aculeiferum Vassal.

\section{REFERENCIAS BIBLIOGRAFICAS}

1. Bentham, G. Revision of the suborder Mimosae. Trans. Linn. Soc. Lond., 30: 335-664. 1875.

2. BURGER,L.M. Estudo anatômico do xilema secundârio de sete espé cies nativas do gênero Dalbergia - Leguminosae Faboideae.Curi tiba, UFPr. $184 \mathrm{f}$. Tese de Mestrado.

3. BURKART, A. Las Leguminosas argentinas silvestres y cultivadas. Bue nos Aires, ACME, 1952. 569 p. 
4. BURKART, A. Leguminosae. In: PARODI,L.R. Enciclopedia argentina de Agricultura y Jardineria. Buenos Aires, ACME, 1959. v.1: 443-512.

5. COMISSION PANAMERICANA DE NORMAS TECNICAS. 30:1-019, novembro, 1973.

6. Cozzo,D. Anatomia del leño secundario de las leguminosas mimosoi deas y caesalpinoideas argentinas silvestres y cultivadas.Rer Inst. Nac. Invest. C. Naturales C. Bot., 2(2): 63-290. 1951.

7. FAHN,A. \& LESHEM,B. Wood fibres with living protoplasts. New Phytoz., 62(1): 91-98, 1963 (Resumo).

8. HARRAR,E.S. Note on starch grains in septate fibertracheids. Tro pical Woods, 85:1-9, 1946.

9. JANSSONIUS,H.H. Mikrographie des Holzes der auf Java vorkommenden Baumarten. 6 vols. Leiden, 1906 - 1936.

io. KLEIN,R. Observações ecolōgicas. In: BURKART, A. Mimosoideas.Ita jấ, Flora Ilustrada Catarinense, $299 \mathrm{p}$.

11. MARCHIORI,J.N.C. Estudo anatômico do xilema secundário e da cas ca de algumas espécies dos gêneros Acacia e Mimosa, nativas no Estado do Rio Grande do Sul. Curitiba,UFPr, 1980. 186 f. Tese de Mestrado.

12. METCALFE,C.R. \& CHALK,L. Anatomy of the Dicotyzedons. Oxford, Clarendon Press, 1972. $1500 \mathrm{p}$.

13. PETTIGREW,C.J. \& WATSON,L. On the classification of Australian Acacias. Austr. J. Bot., 23: 833-847. 1975.

14. ROTH,I. Estructura anatomica de la corteza de algunas especies arboreas venozelonas de Mimosaceae. Acta Botanica Venezueli $c a, 12(1-4): 293-355,1977$.

15. VASSAL, J. Apport des recherches ontogéniques et séminologiques à l'ētude morphologique, taxonomique et philogénique du genre Acacia. Trav. Lab. For. UNiv. Toulouse, 1 (8):1-127. 1972.

16. TEIXEIRA,L.L. Identificação botânico-dendrológica e anatômica da madeira de seis espécies euxilóforas do sudoeste paranaense. Curitiba, UFPr, 1977. 112 f. Tese de Mestrado.

Recebido em agosto, 1982; aceito em setembro, 1982. 
